\title{
THERMOPHYSICAL PROPERTIES OF DEEP EUTECTIC SOLVENT-CARBON NANOTUBES (DES-CNT) BASED NANOLUBRICANT
}

\author{
Rashmi Walvekar ${ }^{1,2, *}$ Amarpreet Singh ${ }^{1}$, Mohammad Khalid $^{3}$, TCSM Gupta $^{4}$, Wong Wai Yin ${ }^{5}$
}

\begin{abstract}
Lubrication is an important aspect when it comes to machinery and equipment in the industry where nanolubricants are extensively being explored as the future of lubricants. Nanolubricants are new-engineered fluids, which are dispersed with nanoparticles that aids in the interface movement by forming a protective layer hence reducing the wear and friction and dissipate the heat generated due to friction. In this research, a new synthetic lubricant is formulated by mixing two or more components of hydrogen bond donors and halide salt that achieves lower melting points compared to individual components. In this study, Glycerol and Polyethylene Glycol 600 (PEG) acts as the HBDs with common salt of Choline Chloride (ChCl). The nanolubricants were synthesised via two-step method by dispersing three different concentration of Functionalised Multi Walled Carbon Nanotubes (F-MWCNTs) of $0.01 \mathrm{wt} \%, 0.05 \mathrm{wt} \%$ and $0.10 \mathrm{wt} \%$ with the aid of ultrasonication. The stability of the suspensions were studied via optical microscopy and visual observation. The addition of FMWCNT increased the resultant dynamic viscosity of the nanolubricant whereas the density was not much affected. Besides that, thermal conductivity showed positive enhancement for glycerol DES nanolubricant and negative enhancement for PEG DES nanolubricant. Thus, this study concludes that the thermophysical properties of DES base fluids and MWCNT have potential to be used as lubricants due to its enhanced physical properties.
\end{abstract}

\section{Keywords: Deep Eutectic Solvent, Carbon Nanotube, Nanolubricant, Viscosity, Thermal Conductivity INTRODUCTION}

Lubricants are used to reduce friction and wear of moving parts that covers a wide range of industrial applications. The various applications include engine oil, automatic transmission fluid, turbines, compressors, pumps, metalworking and hydraulics. However, the chemical composition and physical structure of the lubricant depends on its application [1]. Lubricant forms a protective layer on the surface consisting of either gas, liquid or solid which reduces the friction thus preventing any damage to the surface [2]. A lubricant is characterised by good lubricity, low volatility, low flash point, non-flammability, non-corrosivity and low cost. Besides that, it should also have appreciable viscosity to provide good lubrication for a range of operational temperatures. The lubricant must possess good thermos-oxidative and chemical stability to prevent degradation during operation. The environmental aspect of lubricant should also be considered to prevent any harm to humans and the surroundings with low toxicity and high biodegradability [3]. Various studies have been conducted using ionic liquids (ILs) for their lubricating properties. Qu et al [4], used $1 \mathrm{wt} \%$ of trihexyltetradecylphosphonium bis(2ethylhexyl)phosphate added to the base oil and compared with the zinc dialky-dithiophosphate additive (ZDDP). The results showed better performance at elevated temperatures $\left(100^{\circ} \mathrm{C}\right)$ compared to ZDDP. Khemchandani et al [5] used tributyl(methyl)phosphonium diphenylphosphate, P1444DPP as antiwear additive anti-wear additive and compared against Amine Phosphate (AP) when mixed with biodegradable base stocks. Similarly, tribological improvements were observed by Fan \& Wang [6] using 0.75\% MWCNT in alkyl imidazolium ILs. Other ILs explored that showed improved COF, wear and tribological performance are reported in the literature [7-10 ]. Due to the high cost, toxicity and complex synthesis process of ILs, deep eutectic solvents (DES) are being explored to replace the ILs. DESs which are made up of quaternary salt bounded with Hydrogen Bond Donor (HBD) has melting point lower than the individual component of the DES. DESs have similar properties as Ionic Liquids with more eco-friendly approach in term of that DESs are biodegradable as well as lower production cost [11]. In the view of above foregoing point, DESs have not been explored as a potential lubricant. Therefore, this research focusses on the production of suitable DESs as base fluids for nanolubricants.

\footnotetext{
This paper was recommended for publication in revised form by Regional Editor Sandip Kale

${ }^{1}$ Taylor's University, Jalan Taylor's, Subang Jaya, 47500 Selangor, Malaysia

${ }^{2}$ Xiamen University Malaysia, Jalan Sunsuria, Sepang, 43900 Selangor Malaysia

${ }^{3}$ Graphene \& Advanced 2D Materials Res. Group, School of Sci. and Tech., Sunway University, Malaysia

${ }^{4}$ Research and Development, Apar Industries Limited, Mumbai, India

${ }^{5}$ Fuel cell institute, University Kebangsaan Malaysia, Bangi, 43600 Selangor, Malaysia

*Email adress: rashmi.walvekar@gmail.com, rashmi.walvekar@xmu.edu.my

Orcid id: 0000-0001-8283-1278, 0000-0002-0265-4820, 0000-0002-0799-6344, 0000-0002-5093-1431

Manuscript Received 15 January 2018, Accepted 5 April 2018
} 
The next generation of lubricant can be called as nanolubricant which is formed with the suspension of nanoparticles in the base fluid that are able to reduce friction and wear which depends on the size, shape and amount of nanoparticles added to the base fluid [12]. Nanoparticles when added to existing lubricating oil are able to enhance the lubricity by forming a protective film on the surface and anti-wear property by converting sliding friction to rolling friction [13]. As an example of the effectiveness of addition of nanoparticle was shown in study conducted by Lee et al. [14] where fullerene nanoparticles in mineral oil were able to reduce coefficient of friction by $90 \%$ with a concentration of $0.1 \mathrm{wt} \%$. The CNTs are believed to behave like polymer which initially entangled but rearranges according to the flow direction when certain stress is applied [15]. The dispersion of CNT in oil is capable of affecting the tribological properties of lubricant [16]. Similarly, in the study by Luo et al. [17], the addition of aluminium oxide together with titanium oxide nanocomposite to lubricating oil greatly increased the anti-friction property. The addition of modified graphene platelets as additives in lubricating oil are capable of enhancing tribological properties as the wear resistance and the capability of the lubricant was significantly increased [18]. This research aims at synthesising various DESs, comprising of glycerol and polyethylene glycol (PEG) which acts as HBD and Choline Chlorine ( $\mathrm{ChCl}$ ) as salt at different molar ratios. Functionalised MultiWalled Carbon Nanotube (F-MWCNT) of different concentration is dispersed into the DESs to enhance the thermo-physical, tribological and frictional characteristics of the DES nanolubricants.

\section{EXPERIMENTAL STUDIES Materials}

The common salt used in this research was Choline Chloride ( $\mathrm{ChCl}$ ) purchased from Merck Sdn. Bhd. with purity of $99.0 \%$. The HBDs are industrial glycerol with 97\% purity from Wataka Industries and Polyethylene Glycol 600 from R\&M Chemicals (C.P). The Multi-Walled Carbon Nanotubes (MWCNTs) were functionalised with hydroxyl group and purchased with purity of 95\% from N.E Scientific with $10-20 \mathrm{~nm}$ outer diameter with length of $10-30 \mu \mathrm{m}$.

\section{Preparation of DES-CNT}

The synthesis of DES was conducted for two different HBDs which were glycerol and PEG. The molar ratio for the synthesised two component DES (ChCl-Gly) were based on the literature that has the lowest melting point [19-21], while the three component DESs (ChCl-PEG-Gly) were new DESs that were formulated in this study. The respective molar ratio used for the DESs were shown in Table 1. The DES was prepared by simple mixing and heating with a magnetic stirrer until a homogenous colourless liquid was formed.The nanolubricants or nanofluids were prepared by adding $0.01 \%, 0.05 \%$ and $0.10 \%$ by weight of F-MWCNTs to each of the DES samples in vials as represented in Table 2. The mixture was then sonicated using an ultrasonic water bath with frequency of $37 \mathrm{kHz}$ and $70 \mathrm{~W}$ power rating for a duration of four hours. Parafilm was used to seal tightly the cap of the vials.

Table 1. Different molar ratio of salt: HBDs and their abbreviations

\begin{tabular}{|c|c|c|c|c|}
\hline Salt & \multicolumn{2}{|c|}{ HBDs } & Molar Ratio & Abbreviation \\
\hline \multirow{7}{*}{ Choline Chloride } & \multirow{4}{*}{\multicolumn{2}{|c|}{ Glycerol }} & $1: 2$ & DES 1 \\
\hline & & & $1: 3$ & DES 2 \\
\hline & & & $1: 4$ & DES 3 \\
\hline & & & $1: 5$ & DES 4 \\
\hline & \multirow{3}{*}{$\begin{array}{c}\text { Polyethylene } \\
\text { Glycol } 600\end{array}$} & \multirow[t]{3}{*}{ Glycerol } & $1: 3: 2$ & DES 5 \\
\hline & & & $1: 4: 2$ & DES 6 \\
\hline & & & $1: 5: 2$ & DES 7 \\
\hline
\end{tabular}


Journal of Thermal Engineering, Research Article, Vol. 6, No. 2, Special Issue 11, pp. 53-64, March, 2020

Table 2. Different concentrations of F-MWCNT added to DES with the respective abbreviation

\begin{tabular}{|c|c|c|}
\hline Base & F-MWCNT (Wt. \%) & Abbreviation \\
\hline \multirow{3}{*}{ DES 1 } & 0.01 & NF 1 \\
\cline { 2 - 3 } & 0.05 & NF 2 \\
\cline { 2 - 3 } & 0.10 & NF 3 \\
\hline \multirow{4}{*}{ DES 2 } & 0.01 & NF 4 \\
\cline { 2 - 3 } & 0.05 & NF 5 \\
\hline \multirow{3}{*}{ DES 3 } & 0.10 & NF 6 \\
\cline { 2 - 3 } & 0.01 & NF 7 \\
\hline \multirow{4}{*}{ DES 4 } & 0.05 & NF 8 \\
\cline { 2 - 3 } & 0.10 & NF 9 \\
\cline { 2 - 3 } & 0.01 & NF 10 \\
\hline \multirow{3}{*}{ DES 5 } & 0.05 & NF 11 \\
\cline { 2 - 3 } & 0.10 & NF 12 \\
\cline { 2 - 3 } & 0.01 & NF 13 \\
\hline \multirow{3}{*}{ DES 6 } & 0.05 & NF 14 15 \\
\cline { 2 - 3 } & 0.10 & NF 16 \\
\cline { 2 - 3 } & 0.01 & NF 17 \\
\hline \multirow{3}{*}{ DES 7 } & 0.05 & NF 18 \\
\cline { 2 - 3 } & 0.10 & NF 19 \\
\cline { 2 - 3 } & 0.01 & NF 21 \\
\hline \multirow{3}{*}{} & 0.05 & \\
\hline
\end{tabular}

\section{Properties Measurement}

The stability of the nanolubricant was investigated using optical microscopy and visual observation across a period of time. The optical microscopy used the Swift M10D Series Digital Microscope with images taken at two different magnification of $4 \mathrm{X}$ and $10 \mathrm{X}$ for better understanding of the nanoparticle dispersion. Thermal conductivity was measured as a function of temperature by using the KD2 Pro Decagon Device with uncertainty of $\pm 5 \%$ and jacketed circulating water bath. The thermal conductivity was measured at $25^{\circ} \mathrm{C}, 40^{\circ} \mathrm{C}$, and $60^{\circ} \mathrm{C}$. The viscosity was measured using Haakee Mars III Rheometer from Thermo Scientific with spindle plate size of P35 Ti L and lower plate TMP 35. The viscosity was measured at $25^{\circ} \mathrm{C}, 40^{\circ} \mathrm{C}$ and $100^{\circ} \mathrm{C}$ with two different shear rates of $10 \mathrm{~s}^{-1}$ and $500 \mathrm{~s}^{-1}$. The temperatures were chosen based on the common temperatures used to measure performance of lubricant. The dynamic viscosity was obtained by taking the average viscosity of the two different shear rate at the particular temperature. The density was measured by using the Anton Par DMA $4500 \mathrm{M}$ at temperature of $25^{\circ} \mathrm{C}, 40^{\circ} \mathrm{C}$ and $90^{\circ} \mathrm{C}$. The viscosity was measured at temperature of $100^{\circ} \mathrm{C}$ which was selected due to limitation of the equipment and as the highest temperature to observe the behavior of nanofluid at extreme temperature whereas the heating element of DMA $4500 \mathrm{M}$ limits the temperature to $90^{\circ} \mathrm{C}$ to prevent any damage to the U-tube thus the nanofluids were measured at that particular temperatures.

\section{RESULTS AND DISCUSSION \\ Stability \\ Visual Observation}

The visual observations were carried out and the photographs were taken on Day 0, 1, 2, 3, 4, 11, 18, 25 and 32. Day 0 is referred to the day on which sonication was performed followed by the subsequent day which was Day 1 and so on. All the samples are stable from Day 0 to Day 4. For the glycerol based DESs, samples NF 1 suffered heavy sedimentation whereas NF 10 showed slight sedimentation on Day 11. The sedimentation progressed aggressively for sample NF 1 as the days increased and most of F-MWCNT were settled at the bottom of the vial with minimum dispersion. Sample NF 10 sedimentation was slower whereas at Day 32, F-MWCNT on the upper half of the vial have shown sedimentation. Sample NF 4 and NF 11 began showing very little 
sedimentation on Day 18 and on Day 32 the sedimentation was subjected to a quarter of the vial. Samples NF 2, NF 3, NF 5, NF 6, NF 7, NF 8, NF 9 and NF 12 were still dispersed and showed no sedimentation.

On the other hand, sample NF 16 began to start sedimentation on Day 11 which progressed into Day 32 where most of the nanoparticles were settled at the bottom of the vials. Beside NF 16, all the PEG based DESs were still well dispersed up to Day 32. It was noted that even when sedimentation occurs, once the samples are shaken the nanoparticles tend to re-disperse and forms a homogenous suspension.

It can be concluded that F-MWCNT have longer duration of stability in PEG based DES compared to the glycerol based DES. The higher the concentration of nanoparticles dispersed, the better the stability of the samples. This was also proven in the study conducted by Lamas et al. [22] which states the settling velocity of MWCNT nanofluid reduces as the concentration and the aspect ratio increases which is due to the significant interparticle interaction called as hindered settling. When the aspect ratio and the concentration of nanoparticle is increased, there is a prominent increase of functional groups which tend to repel each other. These repulsions overcome other forces such as gravitational and attractive forces to allow greater stability. Other factors that influences the stability are the viscosity of the basefluid in which the nanoparticles are dispersed and the size of the nanoparticles. In this research, the size of F-MWCNT dispersed are similar thus, the viscosity plays a great role in stability of the samples [22].

Day

0

32

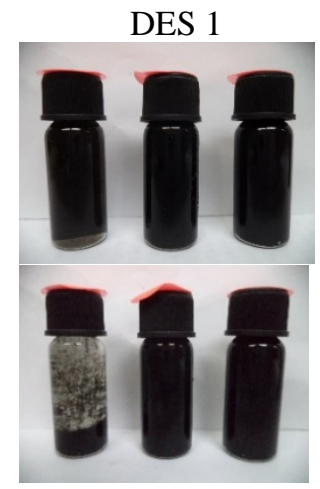

DES 2

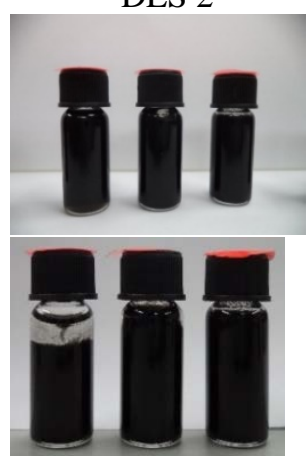

DES 3

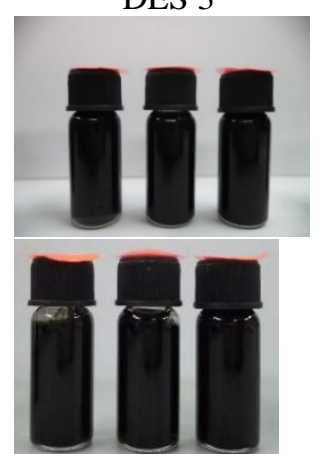

DES 4

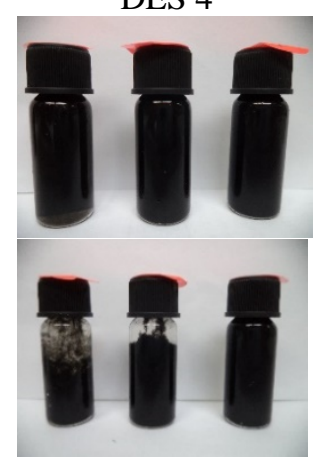

Figure 1. Visual photographs of glycerol DES nanolubricant samples with concentration of $0.01 \mathrm{wt} \%$ (left), $0.05 \mathrm{wt} \%$ (centre) and $0.10 \mathrm{wt} \%$ (right) of F-MWCNT for day 0 and Day 32

Day

0

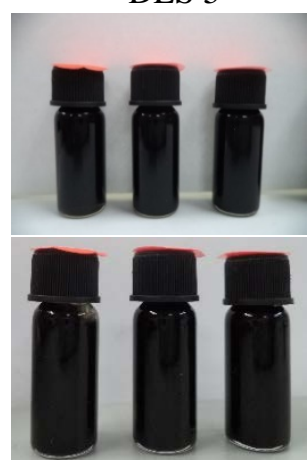

DES 6

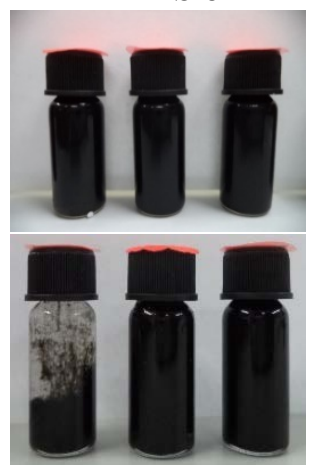

DES 7

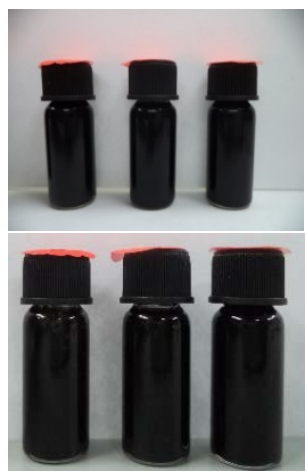

Figure 2. Visual photographs of PEG DES nanolubricant samples with concentration of $0.01 \mathrm{wt} \%$ (left), 0.05 Optical Microscopy

wt\% (centre) and $0.10 \mathrm{wt} \%$ (right) of F-MWCNT for day 0 and Day 32

From Figure 3, it was found that as the concentration of F-MWCNT was increased the size of agglomerates increases for the nanolubricant samples. For the concentration of $0.01 \mathrm{wt} \%$, the nanoparticle are dispersed in the base fluid with relatively spacing between the nanoparticles and smaller formation of clusters. As the concentration increases to $0.10 \mathrm{wt} \%$, the space between the nanoparticles tend to decrease and the size of the cluster formation increases. The highest average cluster size was observed for sample NF 12 and the lowest average size of cluster was for NF 19. When the clusters are compared between the glycerol DES based nanolubricants and the PEG DES based nanolubricants, the PEG DES based nanolubricants were found to have 
Journal of Thermal Engineering, Research Article, Vol. 6, No. 2, Special Issue 11, pp. 53-64, March, 2020

lower cluster size and more dispersed. Therefore, PEG DES based naolubricant samples have better stability in comparison with glycerol DES based nanolubricant which was also supported by the results found in visual observation.

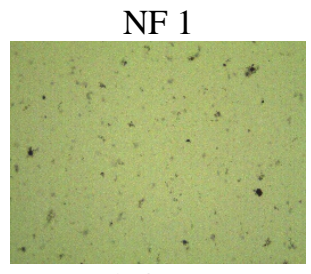

$2.4 \mu \mathrm{m}$

NF 4

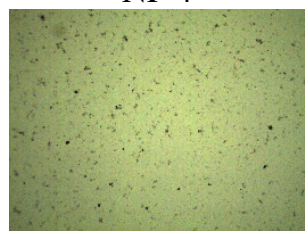

$1.9 \mu \mathrm{m}$

NF 7

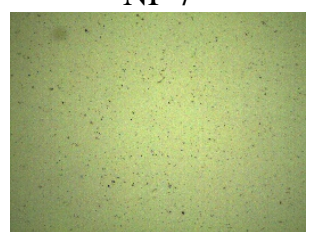

$1.4 \mu \mathrm{m}$

NF 10

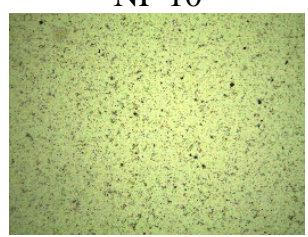

$1.9 \mu \mathrm{m}$

NF 13

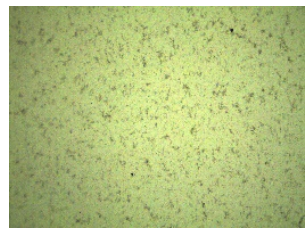

$2.2 \mu \mathrm{m}$

NF 16

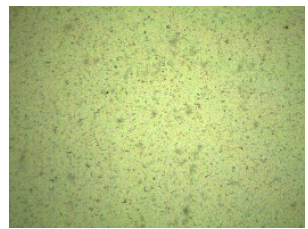

$1.7 \mu \mathrm{m}$

NF 19

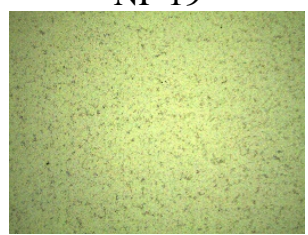

$1.2 \mu \mathrm{m}$

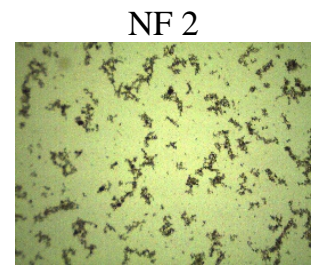

$2.6 \mu \mathrm{m}$

NF 5

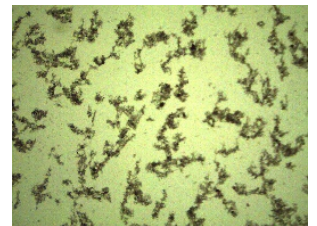

$2.4 \mu \mathrm{m}$

NF 8

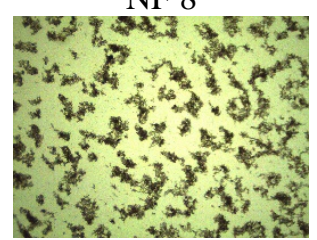

$2.1 \mu \mathrm{m}$

NF 11

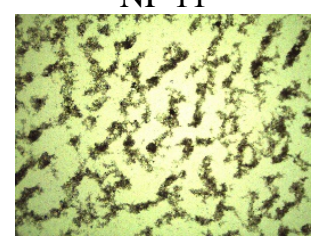

$1.9 \mu \mathrm{m}$

NF 14

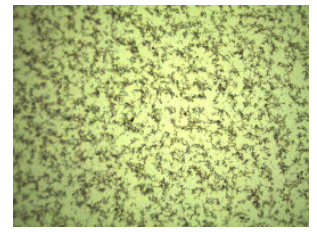

$1.8 \mu \mathrm{m}$

NF 17

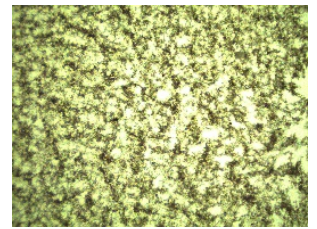

$1.6 \mu \mathrm{m}$

NF 20

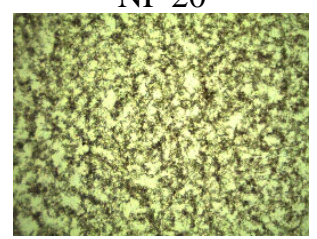

$2.1 \mu \mathrm{m}$

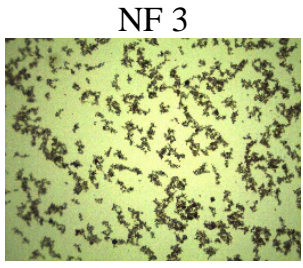

$3.0 \mu \mathrm{m}$

NF 6

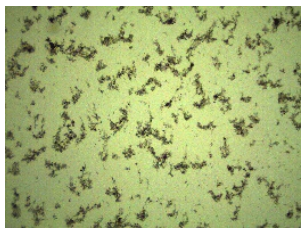

$2.7 \mu \mathrm{m}$

NF 9

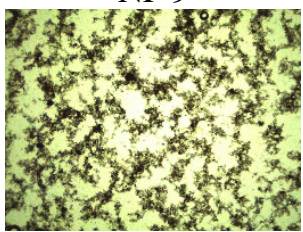

$2.7 \mu \mathrm{m}$

NF 12

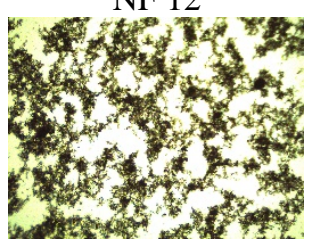

$3.5 \mu \mathrm{m}$

NF 15

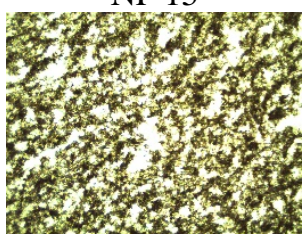

$2.6 \mu \mathrm{m}$

NF 18

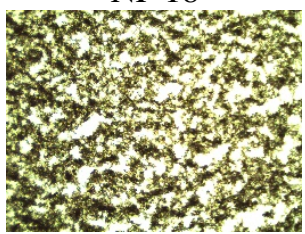

$1.8 \mu \mathrm{m}$

NF 21

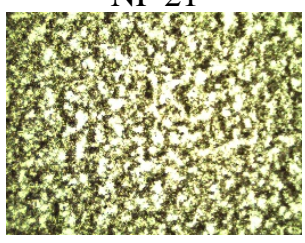

$1.7 \mu \mathrm{m}$

Figure 3. Optical microscopy images of the nanolubricant samples 
Journal of Thermal Engineering, Research Article, Vol. 6, No. 2, Special Issue 11, pp. 53-64, March, 2020

\section{Density}

The density of nanolubricant was investigated with increasing the concentration of F-MWCNT over a range of temperature. The density decreases linearly as the temperature increases for all the samples and the lowest density was obtained at the temperature $90^{\circ} \mathrm{C}$. The increase in temperature leads to thermal expansion of the molecules resulting in reduction in density [23].

Most of the densities of DES 2, 3, 6 and 7 based nanolubricant showed very small variation with addition of F-MWCNT nanoparticles. Apparent increase of densities were observed for DES 1, DES 4 and DES 5 based nanolubricants over the range of temperature shown in Figure 4a, Figure 4d, and Figure 5a. The density of MWCNT nanoparticles are relatively higher and when added to the base fluid will increase the density of the nanofluid [23]. The addition of nanoparticles increases the density which is similar to MWCNT water-ethylene glycol nanofluid found by Kumaresan \& Velraj [24] and also in MWCNT heat transfer oil nanofluid found by Fakoor et al [25] .

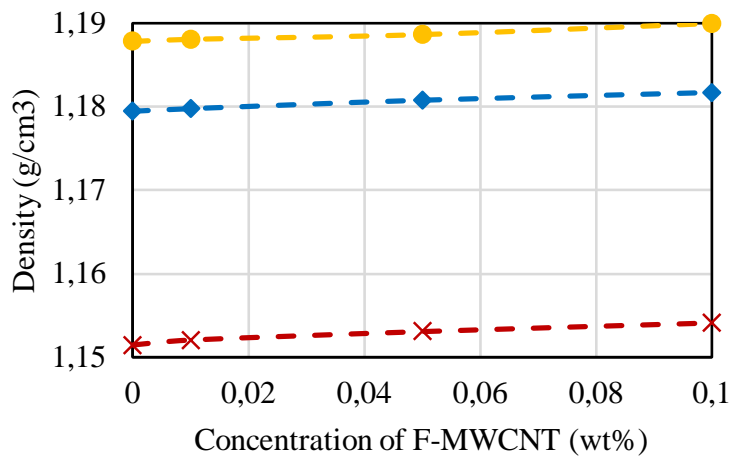

$-\circ-25-40-*-90$

(a)

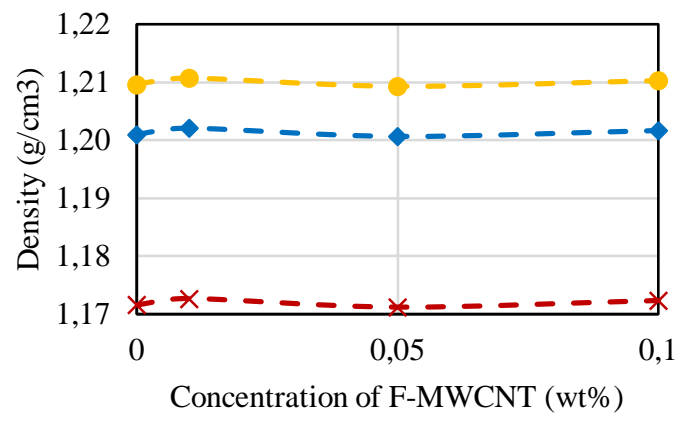

$-\circ-25 \rightarrow-40-*-90$

(c)

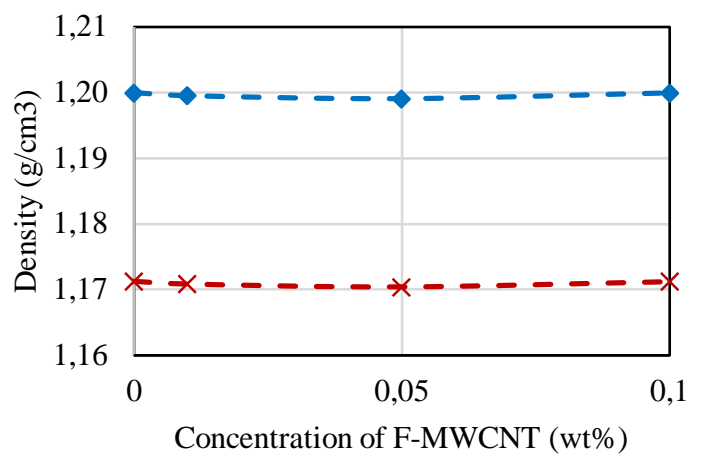

$-\bullet-40-*-90$

(b)

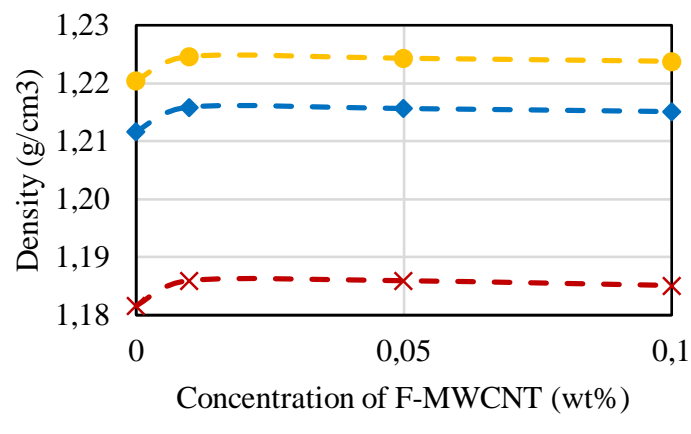

$-\circ-25-40-*-90$

(d)

Figure 4. Density of a) DES 1 B) DES 2 c) DES 3 d) DES 4 based nanolubricants with respect to concentration of F-MWCNT at temperature of $25^{\circ} \mathrm{C}, 40^{\circ} \mathrm{C}$ and $90^{\circ} \mathrm{C}$ 


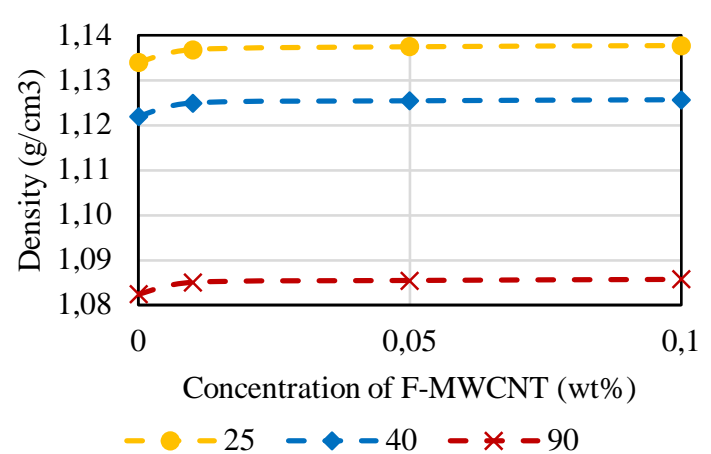

(a)

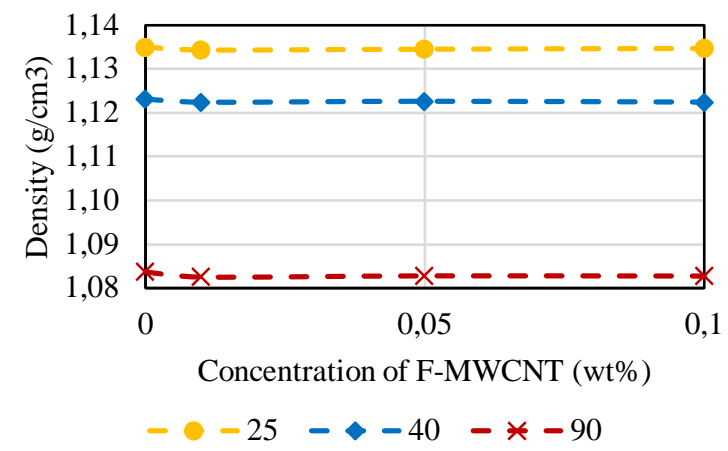

(b)

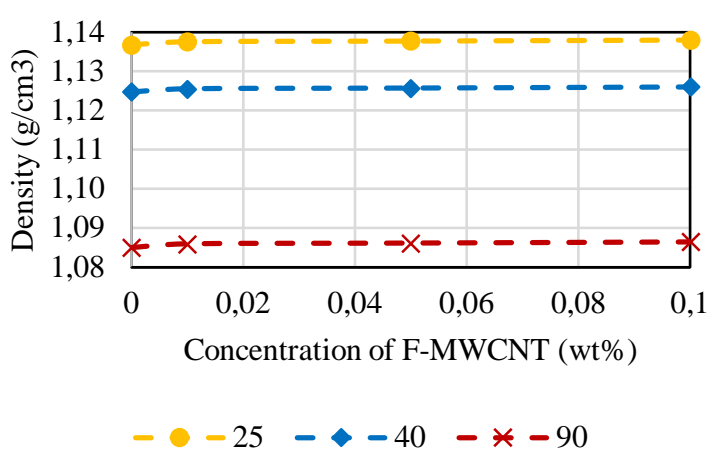

(c)

Figure 5. Density of a) DES 5 b) DES 6 c) DES 7 based nanolubricants with respect to concentration of F-

\section{Viscosity} MWCNT at temperature of $25^{\circ} \mathrm{C}, 40^{\circ} \mathrm{C}$ and $90^{\circ} \mathrm{C}$

The addition of nanoparticles leads to certain enhancement of dynamic viscosity and the percentage enhancement of dynamic viscosity was calculated by using the Eq. 1 for temperature of $25^{\circ} \mathrm{C}, 40^{\circ} \mathrm{C}$ and $100^{\circ} \mathrm{C}$.

$$
\text { Enhancement of Dynamic Viscosity }=\left(\frac{\mu_{n f}-\mu_{b f}}{\mu_{b f}}\right) \times 100 \%
$$

where, $\mu_{\mathrm{nf}}$ is dynamic viscosity of nanalubricant and $\mu_{\mathrm{bf}}$ is dynamic viscosity of base fluid DES.

From Figure 6 and Figure 7, the highest percentage of enhancement was obtain for concentration of FMWCNT of $0.10 \mathrm{wt} \%$ at temperature of $100^{\circ} \mathrm{C}$. The highest enhancement for concentration of $0.10 \mathrm{wt} \% \mathrm{~F}-$ MWCNT was obtained at $255.3 \%$ for NF 12 sample and the lowest enhancement at $44.8 \%$ for NF 6 sample at $100^{\circ} \mathrm{C}$. For some of the samples with concentration of $0.01 \mathrm{wt} \%$ and $0.05 \mathrm{wt} \%$ there were negative enhancement for temperature of $25^{\circ} \mathrm{C}$ and $40^{\circ} \mathrm{C}$ but eventually at $100^{\circ} \mathrm{C}$ the enhancement becomes positive. At lower concentration of F-MWCNT, the dynamic viscosity of the nanolubricant samples were lower than the base fluids due to self-lubricating effect of the nanoparticles that results in negative enhancement [26]. The highest percentage enhancement for concentration of $0.01 \mathrm{wt} \%$ was for sample NF 19 with $11.3 \%$ at $100^{\circ} \mathrm{C}$.

It can be concluded that higher the concentration of F-MWCNT, higher enhancement of dynamic viscosity occurs. Similar enhancement was reported by Halelfadl et al. [27] on CNT/water nanofluids and observed six fold increase in viscosity compared to the base fluid. Another study reports significant increase in relative viscosity when the volume fraction of CNT was increased above $0.055 \%$ [28]. The viscosity of the nanofluid increases non-linearly as the concentration of F-MWCNT increases due to increment of internal viscous shear stress. The structure of nanoparticle increases the surface interaction when dispersed in a base fluid which leads to enhancement of dynamic viscosity. When the temperature was increased, the dynamic viscosity of 
Journal of Thermal Engineering, Research Article, Vol. 6, No. 2, Special Issue 11, pp. 53-64, March, 2020

nanofluid also decreases similar to that of the base fluid (DES) due to the weakening of intermolecular forces of F-MWCNT at elevated temperatures [26].

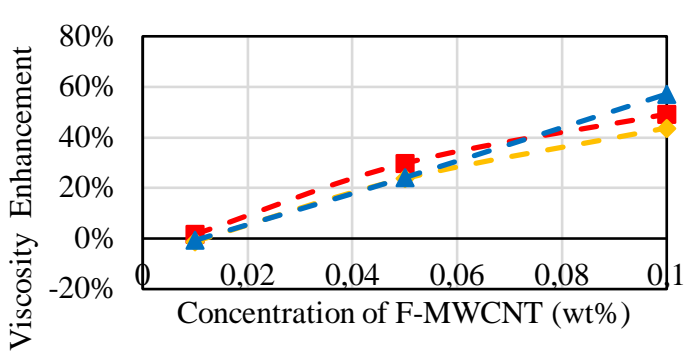

$-\square-25-40-100$

(a)

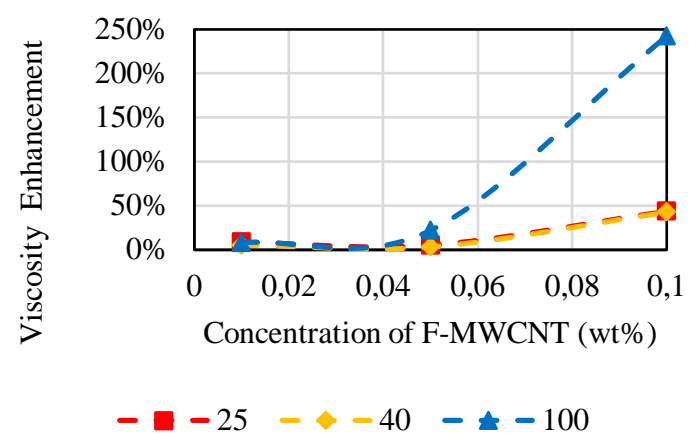

(c)

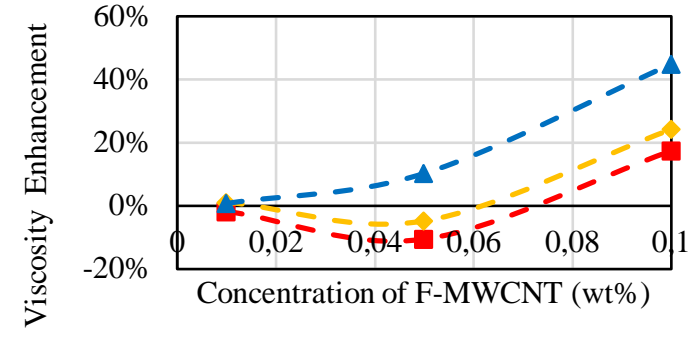

$-\square-25-40-400$

(b)

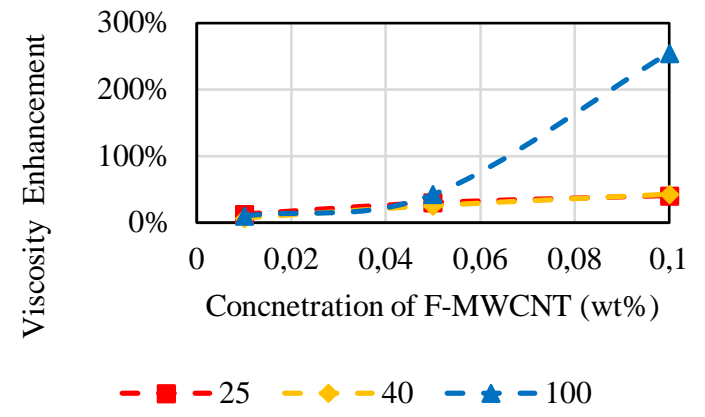

(d)

Figure 6. Percentage enhancement in Dynamic Viscosity of a) DES 1 b) DES 2 c) DES 3 d) DES 4 based nanolubricants with respect to concentration of F-MWCNT at temperature of $25^{\circ} \mathrm{C}, 40^{\circ} \mathrm{C}$ and $100^{\circ} \mathrm{C}$

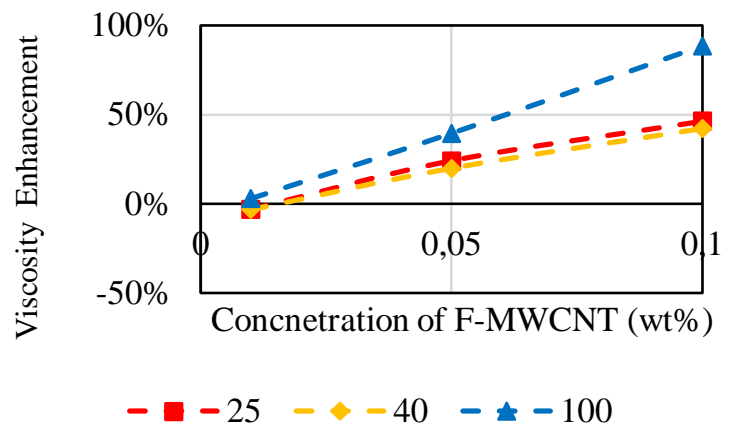

(a)

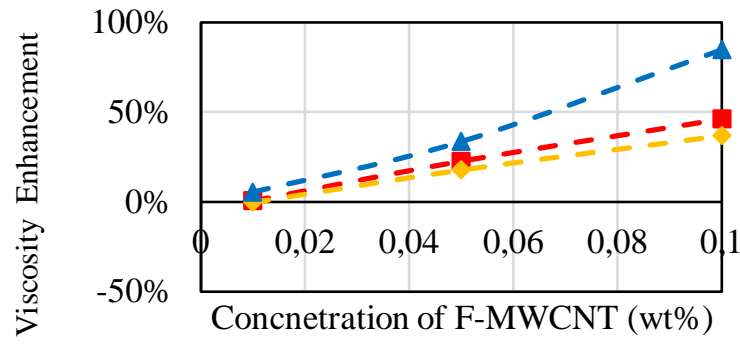

$-\square-25-40- \pm-100$

(b)

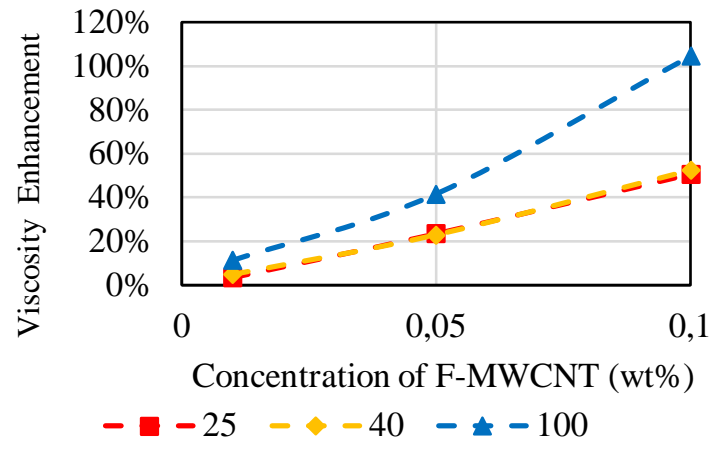

(c)

Figure 7. Percentage enhancement in Dynamic Viscosity of a) DES 5 b) DES 6 c) DES 7 based nanolubricants with respect to concentration of F-MWCNT at temperature of $25^{\circ} \mathrm{C}, 40^{\circ} \mathrm{C}$ and $100^{\circ} \mathrm{C}$ 
Journal of Thermal Engineering, Research Article, Vol. 6, No. 2, Special Issue 11, pp. 53-64, March, 2020

\section{Thermal Conductivity}

The percentage enhancement of thermal conductivity was investigated using the Eq. 2 [26]

$$
\text { Thermal conductivity enhancement }=\left(\frac{k_{n f}-k_{b f}}{k_{b f}}\right)
$$

where, $\mathrm{k}_{\mathrm{nf}}$ is thermal conductivity of nanolubricant $\mathrm{k}_{\mathrm{bf}}$ is thermal conductivity of nanolubricant.

From Figure 8, positive enhancement was observed for all the samples with the highest percentage enhancement in thermal conductivity demonstrated by $0.10 \mathrm{wt} \%$ of F-MWCNT. The highest enhancement was found for NF 12 sample with $8.37 \%$ at $60^{\circ} \mathrm{C}$ and the lowest enhancement was $0.41 \%$ for NF 7 at temperature of $25^{\circ} \mathrm{C}$. Similar results were reported by Ding et al. [29] for CNT in distilled water, Phuoc et al. [30] for MWCNT in deionised water with chitosan and Kumaresan \& Velraj [24] for MWCNT in ethylene glycol-water nanofluid. It can be concluded that increasing the concentration of MWCNT increases the thermal conductivity as more heat was transferred through the nanoparticles [27]. The MWCNT have high thermal conductivity well above 2000 $\mathrm{W} / \mathrm{m} . \mathrm{K}$ and high aspect ratio which makes the MWCNT nanofluids excellent heat transfer liquids. The enhanced thermal conductivity of nanofluids are contributed by the nature of the heat conduction in the MWCNT suspension and the organised structure at the solid/liquid interface [31].

From Figure 9, an opposite behaviour was observed compared to glycerol DES based nanolubricant in Figure 8. The PEG DES based nanolubricant exhibit negative enhancement which means the addition of nanoparticles decreases the thermal conductivity of the samples. Only sample NF 15 and NF 18 showed positive value of $0.2 \%$ and $0.5 \%$ respectively at $100^{\circ} \mathrm{C}$. Other than that, negative enhancement was obtained for the other samples and temperature with highest negative enhancement being $-4.5 \%$ for NF 20 sample at $60^{\circ} \mathrm{C}$. The nanoparticles moving randomly and colliding in the base fluid is known as Brownian motion. Brownian motion plays an important role in enhancement of thermal conductivity when the two particles collide there is solid-solid heat transfer taking place or heat transfer by diffusion. Stoke-Einstein equation is used to express the diffusion constant [32]. There is an increase in viscosity for pure PEG with the formation of DES due to bonding of the three component DES which lead to the negative enhancement as the Brownian motion interrupted.

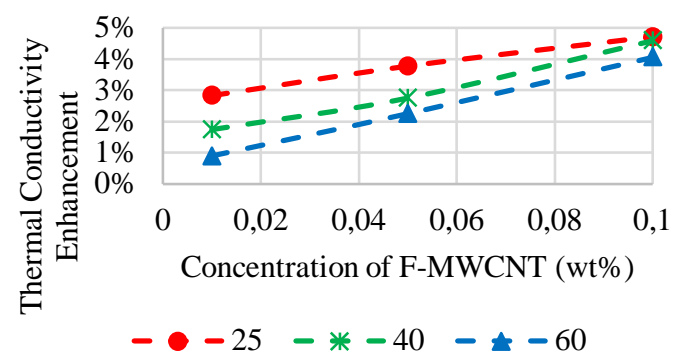

(a)

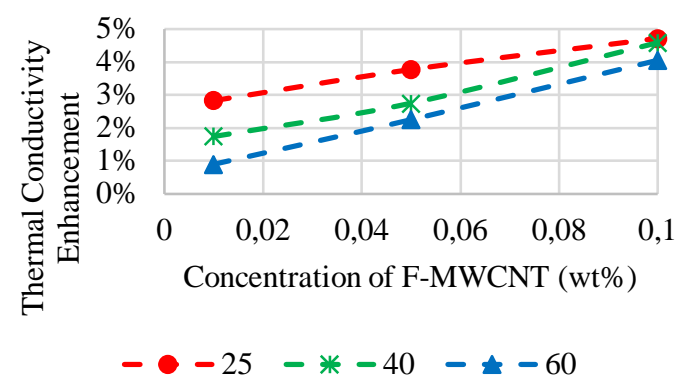

(c)

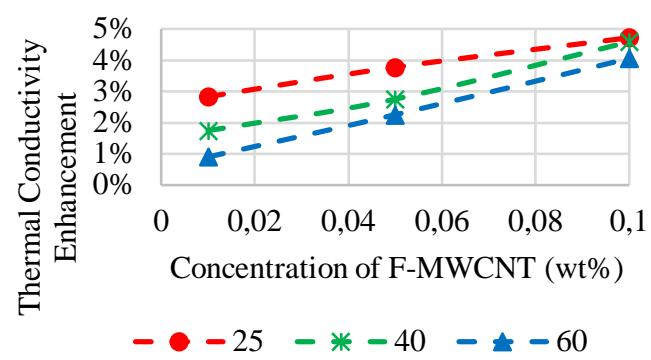

(b)

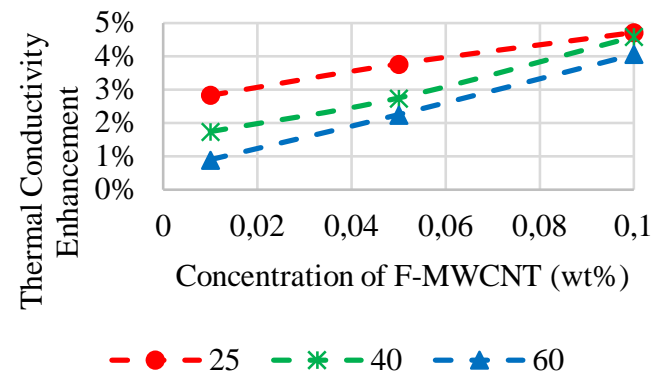

(d)

Figure 8. Percentage enhancement of thermal conductivity of a) DES 1 b) DES 2 c) DES 3 d) DES 4 glycerol based nanolubricants with respect to concentration of F-MWCNT at temperature of $25^{\circ} \mathrm{C}, 40^{\circ} \mathrm{C}$ and $60^{\circ} \mathrm{C}$ 


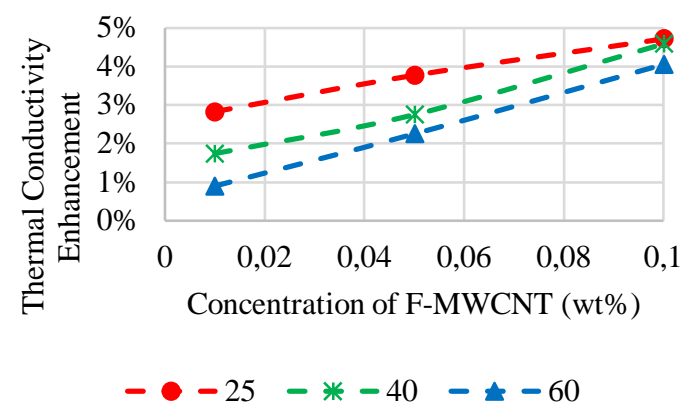

(a)

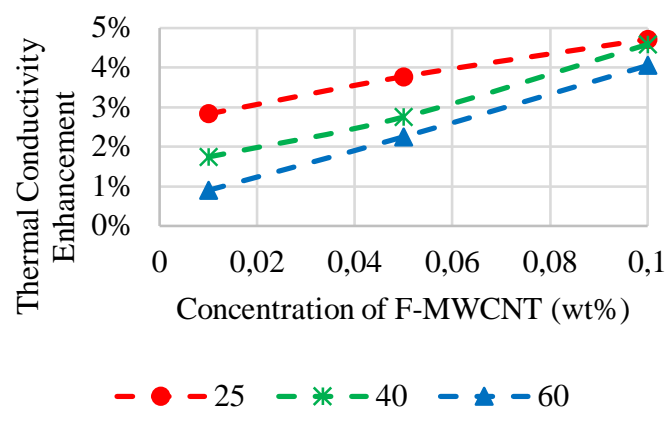

(b)

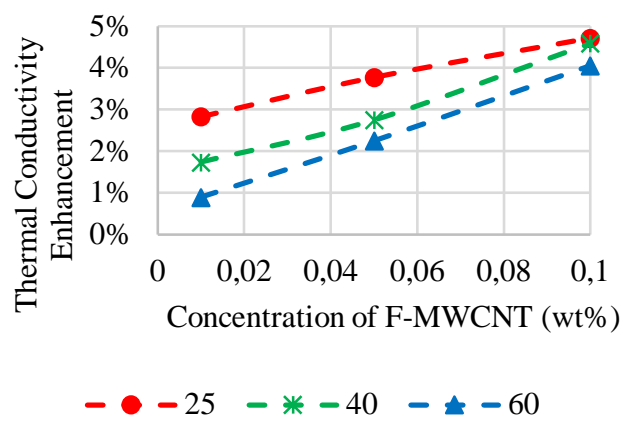

(c)

Figure 9. Percentage enhancement of thermal conductivity of a) DES 5 b) DES 6 c) DES 7 PEG based nanolubricants with respect to concentration of F-MWCNT at temperature of $25^{\circ} \mathrm{C}, 40^{\circ} \mathrm{C}$ and $60^{\circ} \mathrm{C}$

\section{CONCLUSION}

The potential of nanolubricants are vibrantly being explored as the future of the lubrication industry. The formation of glycerol and PEG 600 based DES with choline chloride salt as the base fluid for the nanolubricant. The addition of F-MWCNT with three different concentrations were found to be stable and even the nanoparticle tends to sediment, the nanolubricant can easily dispersed with simple shaking of the samples. The PEG DES based nanolubricant showed better stability and smaller agglomerate size than the glycerol DES based nanolubricant. The density decreases as the temperature increases and most of the sample showed very less variation with the addition of F-MWCNT. Similarly, the dynamic viscosity also decreases with increasing temperature and the addition of F-MWCNT effected the resultant viscosity. The highest enhancement of viscosity was found for concentration of 0.1 wt\% F-MWCNT with 255.3\% for glycerol DES nanolubricant and 104.5\% for PEG DES based nanolubricant. Viscosity plays a vital role when it comes to lubrication and the viscosity of the nanolubricants were found to be sufficient to function as lubricant when compared with other commercial lubricants. Besides that, the glycerol DES based nanolubricant showed positive enhancement of thermal conductivity whereas the PEG DES based nanolubricant showed negative enhancement. The enhancement either positive or negative could be useful when the nanolubricant were specified for certain lubricant application. Nevertheless, more extensive and vigorous research need to be conducted for better understanding of DES-CNT nanolubricants as industrial application. There are a lot of potential of the DES base fluid and nanoparticle combination.

\section{REFERENCES}

[1] Mortier R, Fox M, and Orszulik S. Chemistry and technology of lubricants. Springer 2010; 53.

[2] Stachowiak G W and Batchelor A W, Engineering tribology. $3^{\text {rd }}$ ed. Elsevier, 2005.

[3] Pirro D. Lubrication Fundamentals, in Comprehensive Review of Lubricant Chemistry, Technology, Selection, and Design 2001; 1-22.

[4] Qu J, Luo H, Chi M, Ma C, Blau PJ, Dai S, and Viola MB. Comparison of an oil-miscible ionic liquid and ZDDP as a lubricant anti-wear additive. Tribology International 2014; 71:88-97. https://doi.org/10.1016/j.triboint.2013.11.010 
[5] Khemchandani B, Somers A, Howlett P, Jaiswal K, Sayanna E, and Forsyth M. A biocompatible ionic liquid as an antiwear additive for biodegradable lubricants. Tribology International 2014; 77:171-177. https://doi.org/10.1016/j.triboint.2014.04.016

[6] Fan X, and Wang L. Ionic liquids gels with in situ modified multiwall carbon nanotubes towards highperformance lubricants. Tribiology $\quad$ International 2015; 88:179-188. https://doi.org/10.1016/j.triboint.2015.03.026

[7] Anand M, Hadfield M, Viesca JL, Thomas, Hernández Battez B, and Austen S. Ionic liquids as tribological performance improving additive for in-service and used fully-formulated diesel engine lubricants. Wear 2015; 334-335, 67-74. https://doi.org/10.1016/j.wear.2015.01.055

[8] García A, González R, Hernández Battez, Viesca JL, Monge R, Fernández-González, and Hadfield M. Ionic liquids as a neat lubricant applied to steel-steel contacts. Tribology International 2014; 72:42-50. https://doi.org/10.1016/j.triboint.2013.12.007

[9] Kondo Y, Koyama T, and Sasaki S. Tribological Properties of Ionic Liquids, Ionic Liquids - New Aspects for the Future, Dr. Jun-ichi Kadokawa (Ed.), InTech 2013. https://doi.org/10.5772/52595,.

[10] Pham MQ, Yoon HS, Khare V, and Ahn SH. Evaluation of ionic liquids as lubricants in micro milling Process capability and sustainability. Journal of Cleaner Production 2014; 76:167-173. https://doi.org/10.1016/j.jclepro.2014.04.055

[11] Tang B, Zhang H, and Row KH.“Application of deep eutectic solvents in the extraction and separation of target compounds from various samples,” J. Sep. Sci 2015; 38:1053-1064. https://doi.org/10.1002/jssc.201401347

[12] Wu YY, Tsui WC, and Liu TC. "Experimental analysis of tribological properties of lubricating oils with nanoparticle additives,” Wear 2007; 256:7-8:819-825. https://doi.org/10.1016/j.wear.2006.08.021

[13] Luo T, Wei X, Zhao H, Cai G, and Zheng X. "Tribology properties of Al2O3/TiO2 nanocomposites as lubricant additives,” Ceram. Int 2014; 40:7:10103-10109. https://doi.org/10.1016/j.ceramint.2014.03.181

[14] Lee K, Hwang Y, Cheong S, Kwon L, Kim S, and Lee J. "Performance evaluation of nano-lubricants of fullerene nanoparticles in refrigeration mineral oil,” Curr. Appl. Phys 2009; 9:2:128-131. https://doi.org/10.1016/j.cap.2008.12.054

[15] Ko G. W, Heo K, Lee K, \& Choi M. Thermal and Flow Characteristics of Carbon Nanotube Nanofluids. International Congress for Particle Technology 2007; 151-742.

[16] Joly-Pottuz L, and Ohmae, N. Carbon-Based Nanolubricants, in Nanolubricants (eds J. M. Martin and N. Ohmae), John Wiley \& Sons; 2008.

[17] Luo T, Wei X, Zhao H, Cai G, \& Zheng X. Tribology properties of $\mathrm{Al}_{2} \mathrm{O}_{3} / \mathrm{TiO}_{2}$ nanocomposites as lubricant additives. Ceramics International 2014; 40(7): 10103-10109. https://doi.org/10.1016/j.ceramint.2014.03.181

[18] Rashmi W, Khalid M, Ong SS, and Saidur R. "Preparation, thermo-physical properties and heat transfer enhancement of nanofluids,” Mater. Res. Express 2014; 1(3):32001. https://doi.org/10.1088/20531591/1/3/032001

[19] Smith EL, Abbott AP, and Ryder KS. “Deep Eutectic Solvents (DESs) and Their Applications,” Chem. Rev 2014; 114 (21):11060-11082. https://doi.org/10.1021/cr300162p

[20] Dai Y, Van Spronsen J, Witkamp G. J, Verpoorte R, and Choi Y. H. "Ionic liquids and deep eutectic solvents in natural products research: Mixtures of solids as extraction solvents,” J. Nat. Prod 2013; 76(11): 2162-2173. https://doi.org/10.1021/np400051w

[21] Garcia G, Aparicio S, Ullah R, and Atilhan M. "Deep Eutectic Solvents: Physicochemical Properties and Gas Separation Applications,” Energy \& Fuels 2015; 29:2616-2644. https://doi.org/10.1021/ef5028873

[22] Lamas B, Abreu B, Fonseca A, Martins N, and Oliveira M. “Assessing colloidal stability of long term MWCNT based nanofluids,” J. Colloid Interface Sci 2012; 381(1):17-23. https://doi.org/10.1016/j.jcis.2012.05.014

[23] Leron RB, Wong DSH, and Li MH. "Densities of a deep eutectic solvent based on choline chloride and glycerol and its aqueous mixtures at elevated pressures,” Fluid Phase Equilib 2012; 335:32-38. https://doi.org/10.1016/j.fluid.2012.08.016

[24] Kumaresan V and Velraj R. "Experimental investigation of the thermo-physical properties of waterethylene glycol mixture based CNT nanofluids,” Thermochim. Acta 2012; 545:180-186. https://doi.org/10.1016/j.tca.2012.07.017

[25] Fakoor Pakdaman M, Akhavan-Behabadi MA, and Razi P. “An experimental investigation on thermophysical properties and overall performance of MWCNT/heat transfer oil nanofluid flow inside vertical helically coiled tubes,” Exp. Therm. Fluid Sci 2012; 40:103-111. https://doi.org/10.1016/j.expthermflusci.2012.02.005

[26] Chen L, Xie H, Yu W, and Li Y. "Rheological Behaviors of Nanofluids Containing Multi-Walled Carbon Nanotube,” J. Dispers. Sci. Technol 2011; 32(4):550-554. https://doi.org/10.1080/01932691003757223 
[27] Halelfadl S, Estell P, Aladag B, Doner N, Mar T, Halelfadl S, Estell P, Aladag B, Doner N, and Mar T. "Viscosity of carbon nanotubes water based nanofluids: Influence of concentration and temperature. International Journal of Thermal Sciences 2013; https://doi.org/10.1016/j.ijthermalsci.2013.04.013

[28] Halelfadl S, Maré T, and Estellé P. "Efficiency of carbon nanotubes water based nanofluids as coolants,” Exp. Therm. Fluid Sci 2014; 53:104-110. https://doi.org/10.1016/j.expthermflusci.2013.11.010

[29] Ding Y, Alias H, Wen D, and Williams Ra. "Heat transfer of aqueous suspensions of carbon nanotubes (CNT nanofluids),” Int. J. Heat Mass Transf 2006; 49(1-2):240-250. https://doi.org/10.1016/j.ijheatmasstransfer.2005.07.009

[30] Phuoc TX, Massoudi M, and Chen RH. "Viscosity and thermal conductivity of nanofluids containing multi-walled carbon nanotubes stabilized by chitosan,” Int. J. Therm. Sci 2011; 50(1):12-18. https://doi.org/10.1016/j.ijthermalsci.2010.09.008

[31] Liu MS, Ching-Cheng Lin M, Huang IT, and Wang CC. "Enhancement of thermal conductivity with carbon nanotube for nanofluids,” Int. Commun. Heat Mass Transf 2005; 32(9):1202-1210. https://doi.org/10.1016/j.icheatmasstransfer.2005.05.005

[32] Reddy KP, Panitapu B, and Reddy GA. “Nano Fluids and Heat Transfer Enhancement a Review,” 2016; 7:6. 